\title{
A Concise Enantioselective Synthesis of (-)-Ranirestat
}

\author{
Barry M. Trost ${ }^{*}$, Maksim Osipov, and Guangbin Dong \\ Department of Chemistry, Stanford University, Stanford, California 94305.
}

\begin{abstract}

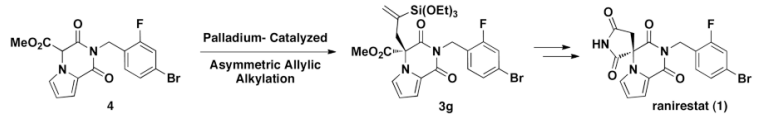

A concise, enantioselective synthesis of the potent aldose reductase inhibitor ranirestat (1) is reported. The synthesis was accomplished employing inexpensive, commercially available starting materials. A palladium-catalyzed asymmetric allylic alkylation (Pd-AAA) of malonate 4 was utilized as a key transformation to construct the tetrasubstituted chiral center in the target.
\end{abstract}

According to the International Diabetes Federation in 2009, more than 285 million people are suffering from diabetes worldwide.1 Over the last two decades, this number has increased by nearly a factor of 10 and continues to grow each year. Hyperglycemia causes serious health problems, including decreased sensory motor function, muscle wasting, bleeding, ulceration of the feet, as well as others. ${ }^{2}$ Many of these complications have been linked to the hyperactivity of aldose reductase, an enzyme of the polyol pathway. Thus, the development of potent aldose reductase inhibitors (ARIs) has become an increasingly important task to help manage complications caused by hyperglycemia. ${ }^{3}$

Ranirestat (1) is a promising aldose reductase inhibitor currently in phase III clinical trials. ${ }^{4}$ Compared to most other ARIs, ranirestat (1) exhibits superior efficacy and low toxicity, allowing for low-end dosing and limited side effects. Ranirestat (1) is a compact, densely functionalized heterocycle.

It contains a spirocyclic tetrasubstituted stereocenter, along with two imide motifs, making its asymmetric synthesis a challenge. Initially, a chiral resolution was used to obtain ranirestat (1) in enantiopure form. ${ }^{5}$ Later, Shibasaki et. al. reported an asymmetric total synthesis of ranirestat using a lanthanide-catalyzed asymmetric conjugate addition of a succinimide derivative which is not commercially available. ${ }^{6}$

Previous work in our group showed that stabilized prochiral nucleophiles can undergo a Pdcatalyzed asymmetric allylic alkylation (Pd-AAA) with various allylic electrophiles to construct the corresponding C-C bonds with high levels of enantioselectivity. ${ }^{7}$ However, use of prochiral amidomalonates as nucleophiles in the Pd- AAA has not been studied. Intrigued by its therapeutic value, we asked if the Pd-AAA reaction of an amidomalonate could provide an efficient solution to construct the target's tetrasubstituted stereocenter.

Our retrosynthetic strategy is outlined in Scheme 1. We planned to construct the A-ring of ranirestat (1) from carboxylic acid $\mathbf{2}$ through amide formation followed by cyclization.

bmtrost@stanford.edu.

Supporting Information Available: Experimental procedures and characterization data for all new compounds. This material is available free of charge via the Internet at http://pubs.acs.org. 
Carboxylic acid $\mathbf{2}$ would arise from a Rucatalyzed oxidative cleavage of olefin $\mathbf{3}$, which would be accessed by employing a Pd-AAA reaction of amidomalonate $\mathbf{4}$ with an allylic electrophile 5. In turn, amidomalonate $\mathbf{4}$ would come from the assembly of commercially available 2trichloroacetylpyrrole (8), benzyl amine $\mathbf{6}$, and methyl bromoacetate (7).

Our synthesis of key intermediate $\mathbf{4}$ was initiated by the $\mathrm{N}$-alkylation of 2trichloroacetylpyrrole $(\mathbf{8})$ with methyl bromoacetate (7), providing trichloroacetyl ketone $\mathbf{9}$ in $78 \%$ yield (Scheme 2). Reaction of trichloroacetyl ketone 9 with benzyl amine $\mathbf{6}$ in the presence of triethylamine in DMF facilitated the tandem condensation-cyclization sequence, forming the B-ring to provide imide $\mathbf{1 0}$ in $68 \%$ yield. Attempts to acylate $\mathbf{1 0}$ using methyl chloroformate only provided the $O$-acylated product. This problem was overcome by treatment of $\mathbf{1 0}$ with Mander's reagent 11, which provided the desired $C$-acylated product 4 exclusively, in near quantitative yield. ${ }^{8}$ It is noteworthy that all compounds in Scheme 2 were prepared on multigram scale and did not require column chromatography for purification.

With malonate $\mathbf{4}$ in hand, the stage was set for the key Pd-AAA reaction. Reaction of $\mathbf{4}$ with allyl tert-butyl carbonate in the presence of catalytic amounts of $\mathrm{Pd}(0)$ and chiral ligand $\mathbf{L s}$ provided the $C$-allylated product 3a in high yield, albeit with poor enantioselectivity (Table 1, entry 1). This transformation proceeded rapidly even in the absence of base with Pd loadings as low as $0.1 \mathrm{~mol} \% .{ }^{9}$ We speculated that substitution on the allyl coupling partner would have an effect on the enantioselectivity of this transformation. Previous work demonstrated that enantioselectivity improves with substitution at either the 2- or 3-position of the allyl electrophile. ${ }^{7}$

We reasoned that substitution of $\mathrm{R}^{2}$ would be flexible since the distal carbon would ultimately be removed via oxidative cleavage. On the other hand, the $\mathrm{R}^{1}$ substituent on the proximal carbon would not be removed in the oxidative cleavage, and would require either $\mathrm{H}$ or an $\mathrm{H}$ equivalent. The effects of allyl substitution are summarized in Table 1. As expected, introduction of substituents larger than $\mathrm{H}$ at either $\mathrm{R}^{1}$ or $\mathrm{R}^{2}$ improved the enantioselectivity. Introducing a phenyl group at $\mathrm{R}^{2}$ (entry 2 ) led to a modest increase in ee, while incorporation of a bromide at $\mathrm{R}^{1}$ (entry 3 ) provided a dramatic improvement. Increasing the steric bulk from $\mathrm{Br}$ to I did improve the ee, however, the product was obtained in modest yield (entry 4). No reaction was observed under the indicated conditions when substituents were introduced at both $\mathrm{R}^{1}$ and $\mathrm{R}^{2}$ (entry 5). Therefore, we focused our efforts on allyl electrophiles substituted at $\mathrm{R}^{1}$.

The most satisfactory results were obtained using vinyl silanes, which in turn are readily obtained through the ruthenium-catalyzed hydrosilylation of the corresponding propargyl alcohol. ${ }^{10}$ Using either benzyldimethylsilyl or triethoxysilyl substituted allyl carbonates provided the allylated product $\mathbf{3}$ in high yield along with high levels of enantioselectivity (entries 6 and 7).

Next, we investigated the effects of solvent on the reaction (Table 2). Enantioselectivities were improved with the use of aromatic solvents while polar solvents like THF and dioxane resulted in lower selectivities. Hexafluorobenzene proved to be the optimal solvent for this transformation, providing the allylated product $\mathbf{3 g}$ in $90 \%$ yield and $84 \%$ ee (entry 3 ). Recrystallization of $\mathbf{3 g}$ in pentane provided $\mathbf{3 g}$ as a single enantiomer in 51-56\% yield from malonate 4 .

With enantiopure vinyl silane $\mathbf{3 g}$ in hand, protodesilylation of the triethoxysilyl group was examined. The choice of fluoride source proved crucial to this transformation. TBAF, TBAT and HF•pyr failed to furnish the protodesilylated product and typically led to substrate decomposition. ${ }^{11}$ Likewise, the use of acidic conditions, like TFA, failed to deliver the desired olefin 3a. Fortunately, using silver fluoride in a mixture of THF, methanol, DMSO, and water, 
provided the olefin 3a in $96 \%$ yield. ${ }^{12}$ The high chemoselectivity of this process led us to develop a one-pot allylation-protodesilylation protocol, which would enhance the operational simplicity of the synthesis and afford olefin 3a directly from the amidomalonate 4 . To our delight, when amidomalonate $\mathbf{4}$ was treated under the optimized allylation conditions (Table 2 entry 3 ) followed by addition of silver fluoride upon completion of the allylation, the desired olefin 3a was obtained in $69 \%$ yield and $84 \%$ ee.

Next, chemoselective cleavage of the terminal methylene fragment of olefin 3a to the corresponding carboxylic acid was investigated. This transformation turned out to be more difficult than we anticipated, as the pyrrole functionality was prone to decomposition in the presence of oxidants. Having surveyed a variety of different conditions, ${ }^{13}$ we found that a combination of $\mathrm{RuCl}_{3}, \mathrm{NaIO}_{4}$, and $\mathrm{K}_{2} \mathrm{CO}_{3}$ facilitated the oxidative cleavage to the desired carboxylic acid. Use of other oxidative conditions including ozonolysis, and $\mathrm{OsO}_{4}$ led either to decomposition of $\mathbf{3 a}$ or mixtures of oxidation products. ${ }^{14}$

Without further purification, the crude acid $\mathbf{2}$ was converted to the acyl chloride by treatment with thionyl chloride in THF, followed by treatment with ammonium hydroxide to afford amide $\mathbf{1 2}$ in 59\% yield from olefin 3a. At this stage, amide $\mathbf{1 2}$ was conveniently cyclized to form the A-ring by treatment with LiHMDS in THF providing ranirestat (1) in near quantitative yield. The analytical data of our material was identical to that reported in the literature. ${ }^{5,6}$

In conclusion, a concise enantioselective synthesis of ranirestat was accomplished starting from readily available materials. The efficiency of the synthesis is demonstrated by its 8 -step length, $14 \%$ overall yield and minimal use of column chromatography. During the synthesis, an efficient Pd-AAA reaction was developed to construct the target compound's spirostereocenter in high yield and enantiomeric purity using amidomalonate $\mathbf{4}$ and a silylsubstituted allyl carbonate 5g. Moreover, the strategy described in this paper should not only provide a ready access to the target molecule $\mathbf{1}$, but also provide strategies for the syntheses of analogues and related targets.

\section{Supplementary Material}

Refer to Web version on PubMed Central for supplementary material.

\section{Acknowledgments}

We thank the National Institutes of Health (GM33049) for their generous support of our programs. We also thank Prof. Masakatsu Shibasaki for providing an authentic sample of ranirestat (1). M.O. is a John Stauffer Memorial Fellow. G.D. is a Stanford Graduate Fellow. Palladium salts were generously supplied by Johnson-Matthey.

\section{References}

1. International Diabetes Federation. Diabetes Atlas. 4th ed. Brussels; 2009. King H, Aubert RE, Herman WH. Diabetes Care 1998;21:1414-1431. [PubMed: 9727886]

2. World Health Organization. Definition, Diagnosis and Classification of Diabetes Mellitus and its Complication. Geneva: 1999.

3. (a) Alexiou P, Pegklidou K, Chatzopoulou M, Nicolaou I, Demopoulos VJ. Current Medicinal Chemistry 2009;16:734-752. [PubMed: 19199934] (b) Varkonyi T, Kempler P. Diabetes, Obesity, and Metabolism 2007;10:99-108.

4. Bril V, Buchanan RA. Diabetes Care 2006;29:68-72. [PubMed: 16373898]

5. Negoro T, Murata M, Ueda S, Fujitani B, Ono Y, Kuromiya A, Komiya M, Suzuki K, Matsumoto J. J. Med. Chem 1998;41:4118-4129. [PubMed: 9767647]

6. Mashiko T, Hara K, Tanaka D, Fujiwara Y, Kumagai N, Shibasaki M. J. Am. Chem. Soc 2007;129:11342-11343. [PubMed: 17722933]

Org Lett. Author manuscript; available in PMC 2011 March 19. 
7. (a) Trost BM, Radinov R, Grenzer E. J. Am. Chem. Soc 1997;119:7879-7880. (b) Trost BM, Brennan MK. Org. Lett 2006;8:2027-2030. [PubMed: 16671773] (c) Trost BM, Frederiksen MU. Angew. Chem. Int. Ed 2005;44:308-310. (d) Ito Y, Kuwano R. J. Am. Chem. Soc 1999;121:3236-3237. (e) You, S-1; Zhu, X-Z.; Luo, Y-M.; Hou, X-L.; Dai, L-X. J. Am. Chem. Soc 2001;123:7471-7472. [PubMed: 11472198]

8. Mander LN, Sethi P. Tetrahedron Lett 1983;24:5425-5428.

9. This experiment was conducted using 1 equiv. 4, 1.1 equiv. 5a, in $\mathrm{PhMe}(0.1 \mathrm{M})$ at $\mathrm{rt}$.

10. (a) Trost BM, Ball Z. J. Am. Chem. Soc 2001;123:12726-12727. [PubMed: 11741457] (b) Trost BM, Ball. J. Am. Chem. Soc 2005;127:17644-17655. [PubMed: 16351094]

11. (a) Trost BM, Ball Z, Thomas J. J. Am. Chem. Soc 2002;124:7922-7923. [PubMed: 12095335] (b) Giraud A, Provot O, Hamze A, Brion J-D, Alami M. Tetrahedron Lett 2008;49:1107-1110. (c) Chakrapani H, Liu C, Widenhoefer RA. Org. Lett 2003;5:157-159. [PubMed: 12529129]

12. (a) Fürstner A, Radkowski K. Chem. Commun 2002:2182-2183. (b) Trost BM, Sieber JD, Qian W, Dhawan R, Ball ZT. Angew. Chem. Int. Ed 2009;48:5478-5481.

13. (a) Miyamoto K, Sei Y, Yamaguchi K, Ochiai M. J. Am. Chem. Soc 2009;131:1382-1383. [PubMed: 19133783] (b) Travis BR, Narayan RS, Borhan B. J. Am. Chem. Soc 2002;124:3824-3825. [PubMed: 11942807] (c) Yu W, Mei Y, Hua Z, Jin Z. Org. Lett 2004;6:3217-3219. [PubMed: 15355016] (d) Travis BR, Narayan RS, Bothan B. J. Am. Chem. Soc 2002;124:3824-3825. [PubMed: 11942807] (e) Criegee R. Angew. Chem. Int. Ed 1975;14:745-752.

14. Carlsen PHJ, Katsuki T, Martin VS, Sharpless KB. J. Org. Chem 1981;46:3936. 
<smiles>[R11]CCCC</smiles><smiles>C=CCC</smiles><smiles>[B]C1(C(=O)O)C(=O)c2cccn2[C@]1(CC(=O)O)C(=O)O</smiles><smiles>[R2]C=C([R2])CO[R6](=O)O[Na]</smiles>

5

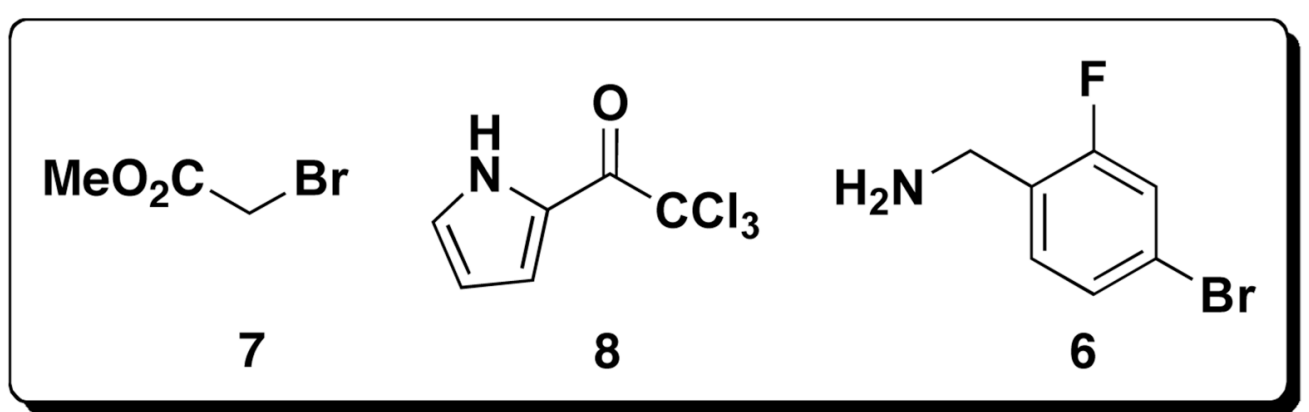

Scheme 1.

Retrosynthetic Analysis 


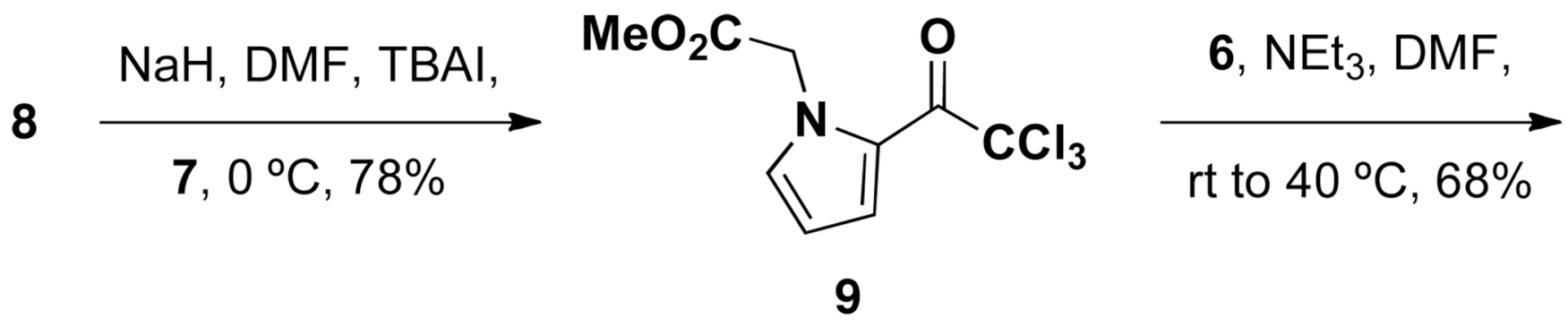

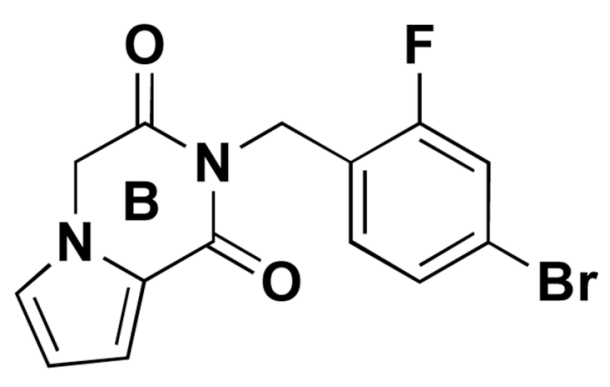

10
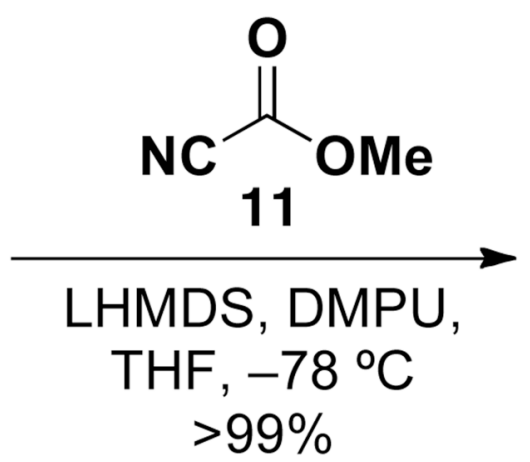

Scheme 2.

Chromatography-free synthesis of amidomalonate 4 
<smiles>C=CC[C@@]1(C(=O)OC)C(=O)N(Cc2ccc(Br)cc2F)C(=O)c2cccn21</smiles>

$3 a$

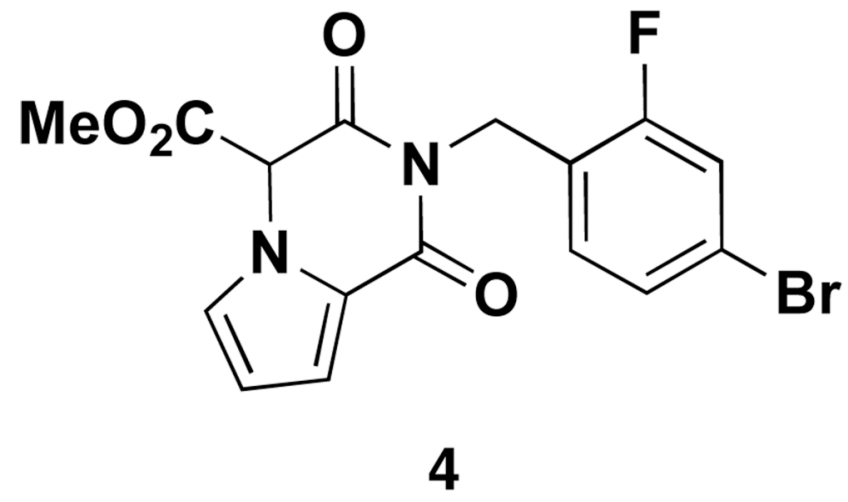

5g, $\mathrm{Pd}_{2}(\mathrm{dba})_{3} \cdot \mathrm{CHCl}_{3}$ $(R, R)-\mathrm{L}_{\mathrm{s}}, \mathrm{C}_{6} \mathrm{~F}_{6}, 4^{\circ} \mathrm{C}$,

Scheme 3.

then

$\mathrm{AgF}, \mathrm{THF}, \mathrm{MeOH}$, DMSO, $\mathrm{H}_{2} \mathrm{O}$, dark, $69 \%, 84 \%$ ee 


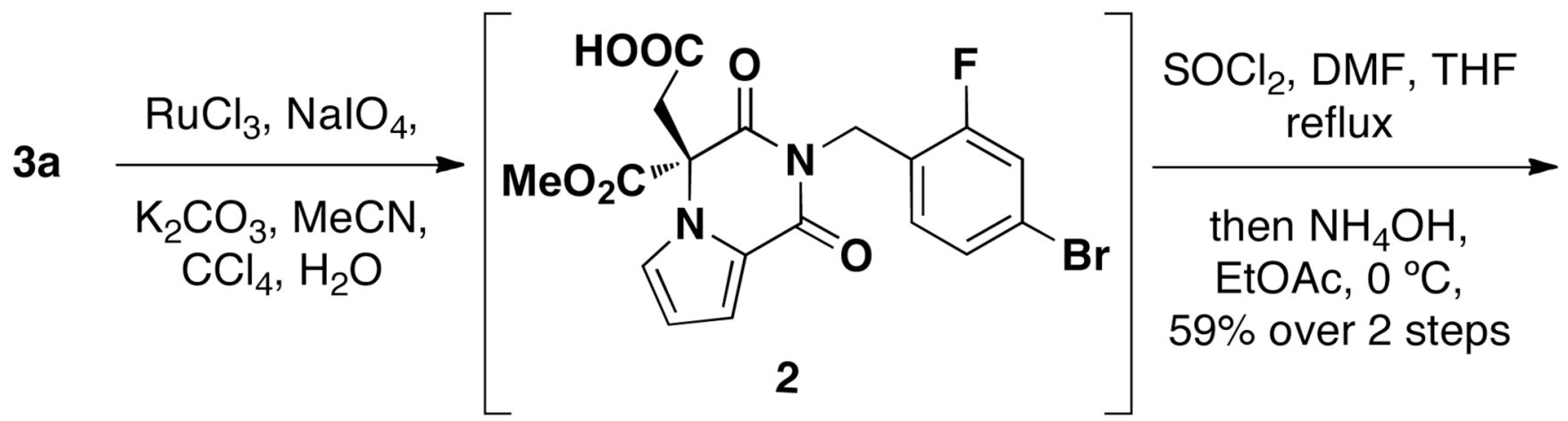<smiles>CO[C@H](CON)[C@@]1(CON)C(=O)N(Cc2ccc(Br)cc2F)C(=O)c2cccn21</smiles>

12<smiles>O=C1C[C@]2(C(=O)N1)C(=O)N(Cc1ccc(Br)cc1F)C(=O)c1cccn12</smiles>

(-) ranirestat (1)

Scheme 4. 


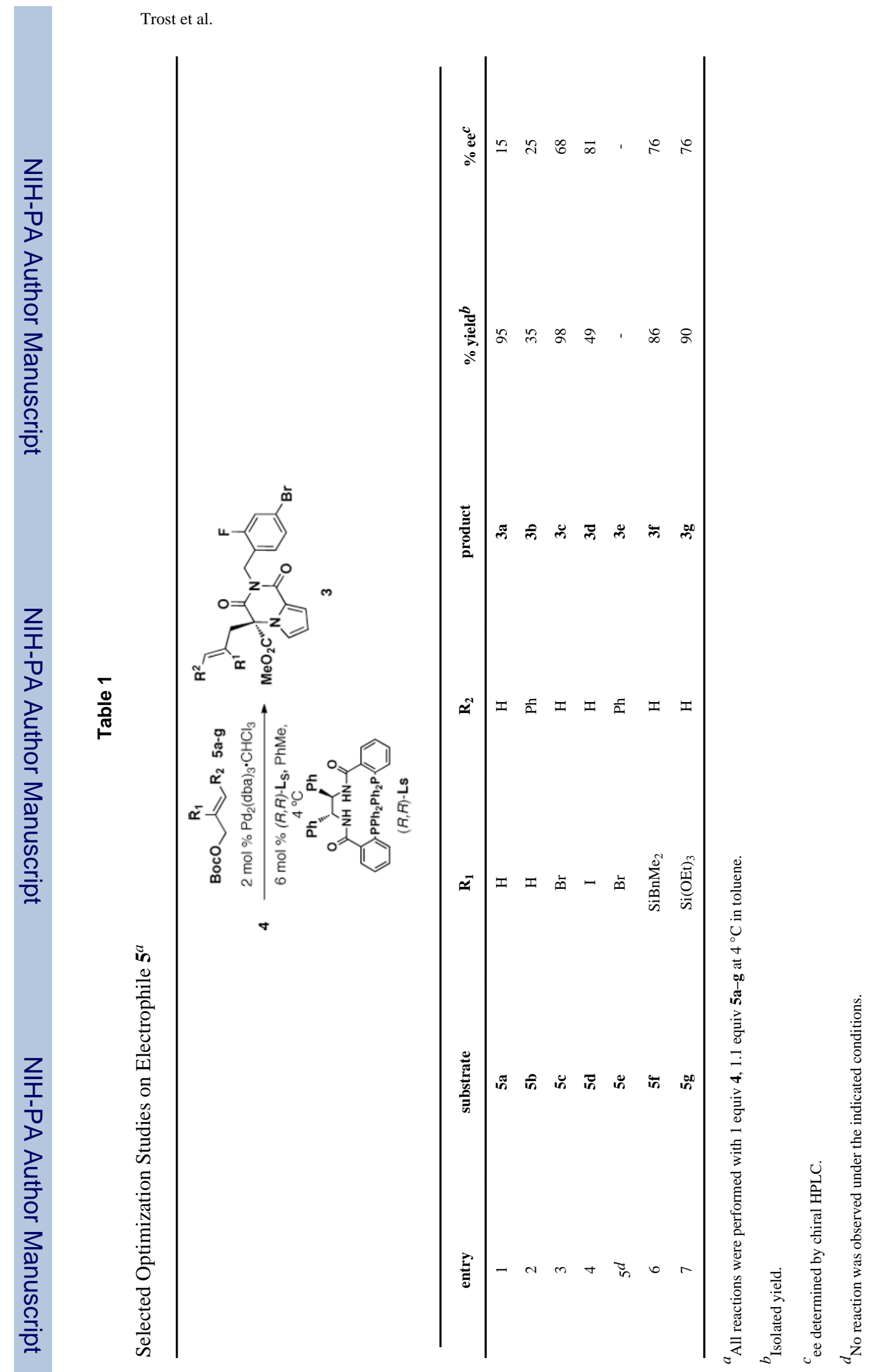

Org Lett. Author manuscript; available in PMC 2011 March 19. 
Table 2

Selected Solvent Optimization Studies ${ }^{a}$

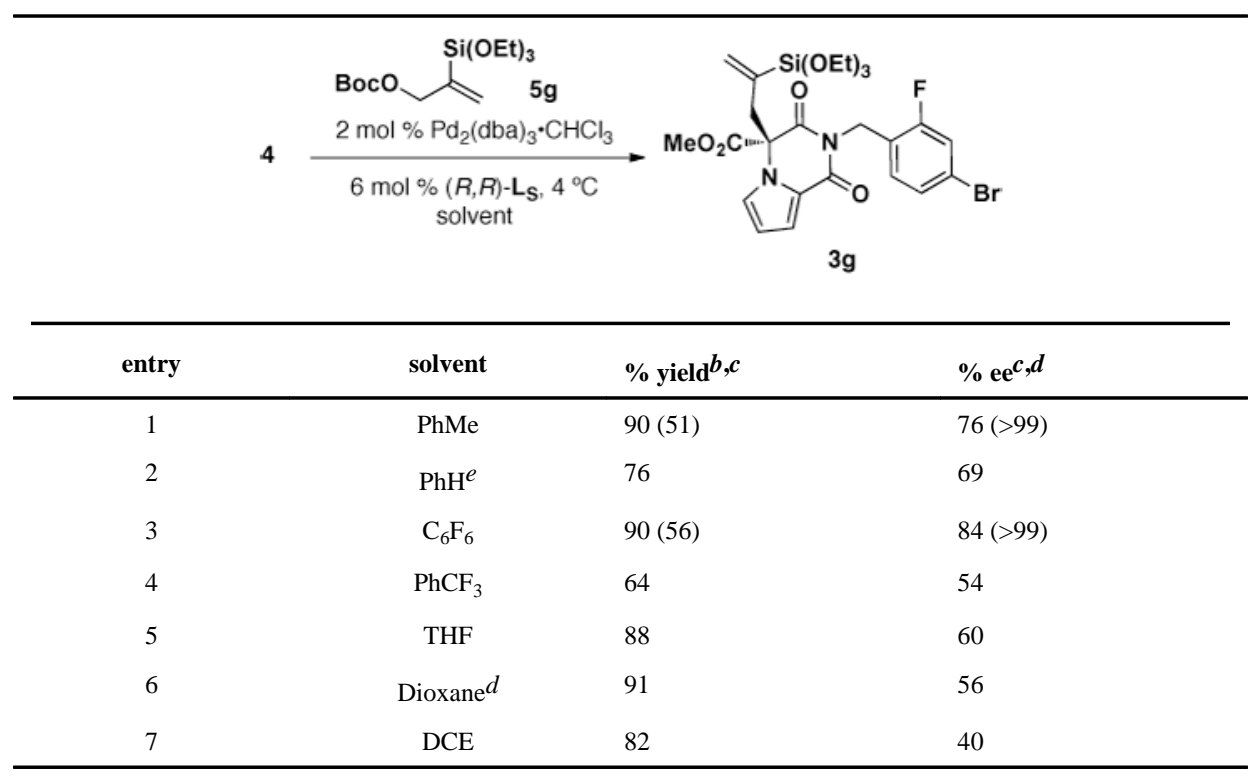

${ }^{a}$ All reactions were performed with 1 equiv $4,1.1$ equiv $5 \mathrm{~g}$ at $4{ }^{\circ} \mathrm{C}$.

$b_{\text {Isolated yield. }}$

${ }^{c}$ Parentheses indicate yield or ee after recrystallization.

$d$ ee determined by chiral HPLC.

$e_{\text {Performed at rt. }}$ 